\title{
DiOTtos
}

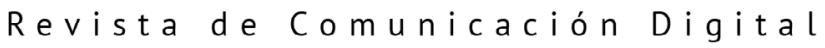

\section{El discurso populista de VOX en las Elecciones Generales de 2019: análisis comparativo de las agendas temáticas en televisión y Twitter}

\section{VOX's populist discourse in the 2019 General Elections: comparative analysis of thematic agendas on television and Twitter}

\author{
David Lava Santos \\ djlava12@hotmail.es \\ Universitat de València
}

\section{Resumen}

Las redes sociales han configurado nuevas formas de consumir la información política en nuestro país. No obstante, la televisión es todavía una fuente de consumo vicaria en lo que a comunicación política se refiere. Ambos medios, redes y televisión, se consolidan en España como los canales preferidos por la ciudadanía para obtener información de carácter político. En un sentido estricto, aunque no se puede demostrar una relación causal entre las apariciones mediáticas de un partido y su irrupción en las cortes, los medios de comunicación, tradicionales y digitales, proveen información fundamental en la formación de la decisión de voto de los ciudadanos. Por ello, esta investigación tiene como objetivo principal analizar las prácticas comunicativas y mediáticas que pueden haber establecido a la formación de ultraderecha, Vox, como tercera fuerza política en España. Para ello, se ha realizado un análisis de contenido con una muestra total de 51 noticias de los informativos nocturnos de TVE y Telecinco, y 264 tuits originales de la cuenta oficial de Twitter del partido, @vox_es. El periodo analizado comprende los días referidos a la campaña electoral del 28 de abril de 2019, y la del 10 de noviembre de ese mismo año. El análisis ha permitido confirmar tendencias como la utilización de un discurso claramente populista por parte de Vox en la red social analizada, o la emisión de noticias en los informativos estudiados cuyos temas no se asemejan a los introducidos por Vox en las publicaciones de su cuenta oficial en Twitter.

\section{PALABRAS CLAVE}

Twitter

populismo

agenda temática

Vox

elecciones 


\begin{abstract}
Social media have set up new ways to consume political information in our country. However, television is still a source of vicarious consumption when it comes to political communication. Both networks and television are consolidated in Spain as the channels preferred by the public to obtain information of a political nature. In a strict sense, although a causal relationship between the media appearances of a party and its irruption in the courts cannot be established, the traditional and digital media provide fundamental information in the formation of citizens voting decisions. The main objective of this article is to analyze the communicative and media practices that may have established the ultra-right formation, Vox, as the third political force in Spain. To do this, a content analysis has been carried out with a total sample of 51 news from the nightly news of TVE and Telecinco, and 264 original tweets from the official Twitter account of the political party, @vox_es. The period analyzed includes the election campaigns of 28 April 2019, and November 10 of the same year. The analysis has confirmed trends such as the use of a clearly populist discourse by Vox on the social network analyzed, or the broadcast of news in the information studied whose topics do not resemble those introduced by Vox in the posts of his official Twitter account.
\end{abstract}

\title{
Keywords
}

populism, thematic agenda, Vox, Twitter, elections

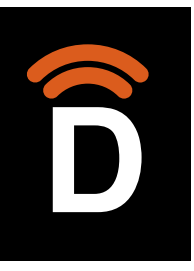

El discurso populista de VOX en las Elecciones Generales de 2019: análisis comparativo de las agendas temáticas en televisión y Twitter

\section{INTRODUCCIÓN}

Las elecciones autonómicas celebradas en Andalucía el 2 de diciembre de 2018 fomentaron el auge de la ultraderecha populista en España. En este contexto, el partido político Vox obtuvo su primera representación electoral, logrando 396.607 votos y 12 de los 109 escaños en el Parlamento andaluz (Martín, 2019: 1). Pero si existe un momento que realmente provocó una alteración en la actividad política española, fue la celebración de las elecciones generales del 28 de abril de 2019. Vox consiguió irrumpir en el Congreso de los Diputados con un total de 24 escaños, una cifra más que considerable para un partido fundado en 2013 y con una ideología fascista basada en una combinación de "nacionalismo y xenofobia (nativismo) y de una visión autoritaria de la sociedad, apegada a los valores de ley y orden" (Ferreira, 2019: 73). Sin embargo, debido a la compleja aritmética parlamentaria ninguna formación política consiguió los apoyos necesarios para formar un gobierno estable y sólido, por lo que el 10 de noviembre de ese mismo año se convocaron unas segundas elecciones. Como resultado de esta votación, de los 350 diputados que conforman el Congreso, 120 fueron para el Partido Socialista Obrero Español (PSOE), 88 del Partido Popular (PP), 52 de Vox, 35 de Unidas Podemos y 10 de Ciudadanos.

Esto supuso la constitución de un gobierno de coalición de izquierdas formado por miembros del PSOE y de Unidas Podemos, pero también implicó que Vox consiguiera 28 diputados más que en las anteriores elecciones, situándose por delante de Unidas Podemos y justo detrás del PP. Por primera vez en 42 años de democracia, un partido 
declarado de extrema derecha se configuró como tercera fuerza política en nuestro país, poniendo fin al "tetrapartidismo" conformado por los partidos PSOE, PP, Podemos y Ciudadanos (López y Valera, 2017: 16) y obteniendo un papel crucial en las decisiones que puedan tomarse durante la legislatura.

En lo que a comunicación política se refiere, ésta "se encuentra en un estado de cambio constante debido a la difusión y consolidación de internet como herramienta utilizada a diario" (Rivas-de-Roca et al. 2020: 228). Aunque la red no haya alcanzado el nivel de interacción que se esperaba, "las redes sociales, y en particular Twitter, han aumentado en importancia en las elecciones" (Rivas-de-Roca et al. 2020: 228). Los nuevos medios digitales han supuesto la aparición de múltiples "plataformas de acceso, y espacios de publicación y difusión de contenidos cada vez más sencillos y generalizados entre el público" (López y Valera, 2017: 17), lo que ha propiciado un cambio en las reglas del juego entre política, medios de comunicación y ciudadanía.

Podemos deducir de la nueva situación que no son los medios de comunicación tradicionales los que tiene el poder exclusivo para generar un mensaje, sino que son los propios ciudadanos y políticos quienes a través de las diversas redes sociales pueden construir información que logre llegar a la opinión pública. Sin embargo, a pesar del indudable protagonismo que suscitan las redes sociales en política, la televisión continúa siendo un elemento clave en la transmisión de información política, y tal y como indicó el informe anual del Digital News Report (2019), la televisión superó en impacto y número de noticias (72\%) a las redes sociales, que contaron con un $40 \%$ de las fuentes de noticias en el año 2019.

La presente investigación se centra en analizar las campañas electorales del 28 de abril de 2019 y la del 10 de noviembre de ese mismo año dirigiendo el interés hacia los contenidos informativos. El diseño propuesto nos permitirá estudiar las siguientes cuestiones: los temas y la valoración que dos de las televisiones de referencia en este país, TVE y Telecinco, han mostrado a la opinión pública sobre la formación política Vox; realizar una comparación entre los temas introducidos por las televisiones y los temas que Vox ha distribuido desde su cuenta oficial de Twitter; $y$, finalmente, verificar si Vox cumple todos los requisitos necesarios para hablar sobre él como un partido populista.

Una vez analizadas estas cuestiones, valoraremos por qué y con qué recursos propios y mediáticos, un partido relativamente joven se ha implantado en el congreso español. Se pretende que los resultados permitan obtener una visión amplia de la estrategia discursiva que ha utilizado Vox en las campañas analizadas, así como las tácticas informativas de las televisiones, de modo que se puedan establecer las tendencias utilizadas por los dos agentes sociales más influyentes en la opinión pública: partidos y medios.

\section{MARCO TEÓRICO}

\subsection{Mediatización y digitalización de la política: acciones informativas de los medios}

La construcción de la realidad política y social es fruto de la interacción entre los medios de comunicación y los actores políticos. En esencia, diversos estudios se han centrado en comprender el efecto de los medios sobre el público, pero, sobre todo, se han encargado de definir cuál de los dos actores anteriormente planteados, medios o 
políticos, influye sobre quién; los medios de comunicación sobre el discurso político, o, por el contrario, los políticos ejercen un poder sobre los medios (López, 2017: 574). Entre otras tendencias en comunicación política, destaca la consolidación de los medios de comunicación tradicionales como "espacio primordial de debate público y de formación de la opinión pública en las democracias contemporáneas", que ha consolidado el modelo de política mediatizada (Valera y López, 2014: 42) o mediatización de la política (Mazzoleni, 2004: 16).

En palabras de Strömbäck (2008: 232), la mediatización apunta a un proceso en el curso del cual los medios ganan influencia sobre la vida política hasta convertirse en "instituciones centrales en la regulación de la misma". Junto a esta capacidad regulativa de los medios de comunicación, Mazzoleni y Schulz (2010: 251) señalan que la mediatización propicia la pérdida de autonomía por parte de los partidos y líderes políticos, convirtiéndose en actores dependientes de los medios de comunicación. En cualquier caso, aunque los medios de comunicación están presentes en el núcleo de las estrategias comunicativas que los partidos políticos y sus principales dirigentes realizan para llegar a la opinión pública (Casero y Yeste, 2014: 10), esto no implica que el desarrollo de la mediatización obedezca al mero hecho de la existencia de los medios en el entorno social, sino que apunta a un proceso cuyo grado de desarrollo se determina atendiendo a cuatros dimensiones (Martínez-Nicolás, Humanes y Saperas, 2014: 43)

"la relevancia que adquieran los medios como fuente de información política; el nivel de independencia con respecto al poder político en su funcionamiento ordinario; el grado en que la cobertura y el tratamiento informativo de la política se rijan por criterios profesionales autónomos (lógica mediática), [...]: y, en fin, al grado en que el propio sistema político asuma y adopte las pautas y modos característicos de aquella lógica mediática para asegurarse el acceso a los medios" (Martínez-Nicolás, Humanes y Saperas, 2014: 43).

En efecto, se evidencia que las propias acciones y decisiones que los políticos efectúan cotidianamente se adoptan con la "mentalidad puesta en el atractivo mediático" (Davis, 2007: 186-191; Palau, Carratalá y Valera, 2017: 603). De acuerdo con esta lógica, la política pasa a realizarse preeminentemente a través de los medios de comunicación, y en el caso específico de las campañas electorales (Gamir, 2015: 195), la mediatización ocupa un papel central en el proceso electoral (Mancini, 1995: 147, citado en Gamir, 2015: 195), de forma que los medios de comunicación de masas, entre los que destaca la televisión, "actúan conjuntamente con los aparatos del partido, y, a menudo les obligan a adaptarse a sus propias lógicas" (Mancini, 1995: 147).

En este contexto, la mediatización de la política implica conocer sustancialmente el concepto de lógica mediática. Peris et al. (2020: 56) asocian lógica mediática al hecho de que los medios imponen unas formas de representación al resto de actores sociales, en este caso políticos, "cuyo protagonismo informativo dependerá de su capacidad para ajustarse a ellas". De manera similar, Hjarvard, (2016: 240) señala que la lógica mediática es la influencia que los medios de comunicación ejercen en "cómo se organiza el material, el estilo en que se presenta, la focalización o énfasis sobre las características particulares de conducta y gramática de la comunicación mediática (Altheide y Snow, 1979). No obstante, aunque la política tenga que aceptar la lógica 
mediática, Casero y Yeste (2014: 10) también sostienen que los medios, en ocasiones, tienen que "acomodarse a la lógica impuesta por la política".

La capacidad del periodismo para adaptar la lógica política a la mediática estaría condicionada, según Humanes, Martínez-Nicolás y Saperas (2013: 716), por las características del sistema político-mediático en el que los propios medios ejercen su función informativa. Así, "manejando factores relativos al funcionamiento de los sistemas político y comunicativo en las democracias occidentales" (Martínez-Nicolás, Humanes y Saperas, 2014: 45), Hallin y Mancini (2011) distinguen tres modelos diferentes políticosmediáticos: el democrático corporativo, propio de los países del norte y el centro de Europa; el liberal, característico del mundo anglosajón; y, finalmente, el pluralista polarizado, de países del mediterráneo europeo.

El sistema de medios español se corresponde con el modelo pluralista polarizado (Palau, Carratalá y Valera, 2017: 604) y está caracterizado por difundir "enormes dosis de partidismo y estar claramente alineado en torno al eje izquierda-derecha" (Valera, 2012: 225). En esencia, el sistema pluralista polarizado está estrechamente relacionado con el concepto de paralelismo político, que indica el grado de concordancia entre medios y actores políticos (Humanes et al. 2013: 567). Sin embargo, aunque los ciudadanos en España atribuyen un elevado grado de politización de los medios, éstos no llegan a identificarse con ninguna ideología política, pero sí que apoyan puntualmente alguna de las propuestas de algún partido cuando coinciden con su línea editorial (Casero, 2012: 32).

Numerosas investigaciones se han encargado de comprobar el grado de paralelismo político en los medios tradicionales, y en especial relevancia la televisión. Así, el trabajo de Humanes et al (2013: 579) demostraba que en el modelo mediático español no existe un fuerte paralelismo político entre la televisión y el sistema político español, pero esto no era "óbice para que, en los asuntos políticos más importantes, los programas informativos tomen partido por una u otra posición a través de la selección de los temas, su tratamiento y valoración".

Llegados a este punto, y como comentábamos al inicio del epígrafe, la construcción de la realidad social determinada por el poder de los medios de comunicación pone de manifiesto cómo la agenda mediática es capaz de configurar y dirigir la opinión pública (Valera y López, 2014: 43). De este modo, se asume la importancia de los medios de comunicación a la hora de presentar y "enmarcar a la ciudadanía los principales temas de agenda" (Navarro y Rodríguez, 2017: 144), y por supuesto, de seleccionar algunos aspectos "de la realidad percibida y hacerlo más prominentes en un texto comunicativo" (Entman, 2007: 135). En efecto, los marcos conceptuales de la mediatización permiten determinar dos pilares que ésta ejerce sobre el ejercicio político y mediático: la agenda setting y el framing.

Los medios de comunicación influyen en las preocupaciones públicas de los ciudadanos porque transfieren relevancia en torno a un conjunto de temas específicos, lo que propicia que estos sucesos sean concebidos por el público como las cuestiones más relevantes en la realidad social. Siendo diversas las aportaciones empíricas que se encargan de definir la teoría del establecimiento de la agenda (McCombs y Shaw, 1972; McCombs, 2004), Dearing y Rogers (1996: 22) realizan una aproximación específica y precisa de ésta, sugiriendo la idea de que el proceso de agenda es una competencia 
continua en la que se propone un tema específico o "issue" para captar la atención de los medios de comunicación, el público y las élites políticas.

Indicamos que esta definición es la más precisa porque, como han señalado López y Valera (2014: 43), resultaría reduccionista asumir que los "medios sean los únicos actores que confeccionan la agenda pública", y bajo la perspectiva de la agenda building, Sádaba y Rodríguez (2007: 188) coinciden en señalar que en la sociedad existe una "competencia de significados, como son los actores políticos, sociales, etc." que pugnan entre ellos para intervenir en el espacio público. Se produce así una competencia entre agendas (Sádaba y Rodríguez (2007: 188) por la cual los actores sociales "alimentan el discurso mediático" (López y Valera, 2014: 43).

Junto a esta capacidad para fijar los temas relevantes para el debate público, "los medios de comunicación también nos brindan explicaciones sobre las causas y consecuencias relacionadas con las cuestiones destacadas en sus agendas" (D'Adamo, Beaudoux y Freidenberg, 2007, citados en Aruguete, 2011: 67 y ss), esto es, la teoría del framing. Existe un debate abierto sobre las diferencias y similitudes entre la agenda setting y el framing, pero ésta última "plantea investigar la forma en que se presentan los asuntos públicos en los contenidos mediáticos, la interpretación que los medios promueven en los contenidos mediáticos y cómo estos enfoques afectan a la comprensión y el procesamiento cognitivo de la información por parte de la audiencia (Pan y Kosicki, 2001: 35 y ss). Por ende, el framing implica analizar el discurso mediático en relación al contexto en el que éste se produce, indagar en la relación que mantienen los elementos del texto entre sí, y las causas y consecuencias de los asuntos públicos que presentan los medios (Gamson y Modigliani, 1989: 2).

Abordadas las teorías del establecimiento de la agenda y el framing en el ámbito operativo de la mediatización, cabe destacar que con el surgimiento de la 'World Wide Web'y el desarrollo de plataformas digitales (Dader, 2009:1), durante los últimos años se ha consolidado el auge de escenarios donde los medios de comunicación tradicionales son despojados del rol preferente que se les había otorgado (Chadwick, 2013). Tal y como indican Baviera, García-Ull y Cano-Orón (2017: 168), la adopción de redes sociales como Twitter, Facebook e Instagram y su uso para difundir información política ha sido tan notable que no sólo ha supuesto un impacto en la agenda mediática, sino que ha logrado determinar un nuevo escenario para el debate político; la digitalización.

"Desde el momento en que las redes sociales se catapultaron como herramientas de éxito en comunicación política -diversos estudios sitúan este aterrizaje en 2008, [...]los partidos políticos se han visto obligados a competir por el alcance e influencia de sus mensajes también en esta esfera mediática. El resultado está siendo lo que Chadwick (2013) denomina sistema mediático híbrido, cuya principal característica es la independencia de una lógica vertical de transmisión y recepción de contenidos con otra lógica de circulación, recirculación y negociación de la información política, propia de la comunicación en internet" (Baviera, García-Ull y Cano-Orón, 2017: 168).

En esta coyuntura, las plataformas sociales permiten que los actores políticos se conviertan en productores y difusores de sus propios mensajes, "prescindiendo de la mediación periodística y controlando el mensaje desde su concepción hasta su transmisión. Algo que trastoca, al menos en teoría, las bases de la mediatización" (Casero, 2014: 10). De esta forma, el modelo tradicional de comunicación política que 
se caracterizaba por el papel central de los medios de comunicación en la creación de contenidos políticos, convive con la afluencia de un espacio "comunicativo complejo, caracterizado por la enorme diversidad que adquiere la circulación de los mensajes" (López et al. 2015: 216) y la mayor fragmentación de los públicos (Waisbord, 2020: 265)

De esta forma, redes sociales como Twitter, Facebook o WhatsApp se consolidan como herramientas fundamentales en comunicación política, y figuras sociales de todo tipo "como partidos, gobiernos o la propia sociedad civil" las utilizan en su afán por transmitir o recibir información (Campos- Domínguez, 2017: 785). Sin embargo, la fragmentación de los contenidos ha propiciado, especialmente en Twitter, la aparición de cámaras de eco, burbujas filtro (Waisbord, 2020: 265) o la homofilia (Valera, Calvo y López, 2018: 59), entre otras.

Estos conceptos expresan el modo en que los votantes resignifican y se adhieren al discurso de las élites (Aruguete, 2019: 23). Así, como los usuarios no pueden acceder a toda la información que se transmite por la web, acceden a una porción de mensajes que aceptan y difunden. Los algoritmos sistematizan la huella digital de los usuarios y les devuelven los mensajes que son política e ideológicamente afines a sus preferencias, consolidando la segregación homofílica (Aruguete, 2019: 24), es decir, la idea que establece que "la mayoría de las conversaciones que tienen lugar en foros explícitamente políticos están dominadas por personas afines y con usuarios que comparten ideas políticas" (Valera, Calvo y López, 2018: 59). Asimismo, las burbujas filtro "mantienen a la ciudadanía en mundos cerrados ideológicamente, sin apertura a visiones diferentes" (Waisbord, 2020: 265). Esta combinación de procesos acrecienta, aún más si cabe, la polarización política, que a su vez se encuentra estrechamente relacionada con el fenómeno populista (Hadlin, 2018: 86).

\subsection{Populismo en política}

Las recientes crisis migratorias y económicas surgidas en Europa desde el año 2008, cuyo principal efecto ha sido la polarización ideológica y social que se ha materializado en el escenario político actual, han conseguido incrementar el surgimiento de partidos populistas en Europa y en el resto del mundo (Öner, 2020, 14). Así, por ejemplo, nos encontramos con partidos como la Agrupación Nacional en Francia, la Liga Norte de Italia, o el propio partido Vox en España (Pérez-Curiel, 2020: 175), que han conseguido consolidarse como formaciones que juegan un papel fundamental en la arena política cotidiana.

El fenómeno y la victoria electoral de Trump en enero de 2017 (Almansa, 2019: 157), Bolsonaro en Brasil, y la consolidación de Vox como tercera fuerza política en España, entre otros acontecimientos, han conseguido que el populismo sea hoy en día un término marcado por su gran uso mediático (Errejón, 2015: 132), político y social, pero cuya definición aún es "notoriamente vaga" y ambigua (Cannovan, 1999: 3), a la vez que cargada de interpretaciones negativas (Mudde, 2004: 543). Muchos son los autores que han intentado definir el fenómeno "populismo". López (2017: 577) lo considera como una forma de hacer política que renuncia a los intermediarios en pro de una comunicación más directa entre el líder y el pueblo. Para Engesser, Fawzi y Olof (2017: 2) el populismo puede ser concebido como una ideología, un estilo o una estrategia. Por su parte, Mudde (2004: 543) entiende el populismo como la aplicación de cuestiones simples, emotivas y sentimentales por parte de los políticos oportunistas en su afán de convencer a los votantes. 
Sin embargo, aunque cada autor discrepe conceptualmente y aporte una definición distinta para este fenómeno, es cierto que los investigadores coinciden en destacar dos elementos centrales en el populismo; el "pueblo" y la "élite". Por su parte, el término pueblo es un constructo abstracto que pretende idealizar a la población con las características "más nobles, auténticas y puras" (Savarino, 2006: 77-94), y se identifica con las clases populares contrapuestas a las oligarquías dominantes que les marginan; la "élite" que abusa de su poder y es "corrupta", explotadora" e "incompetente" (Albertazzu y McDonnell, 2008 citados en Engesser et al. 2017: 1112). Alonso (2018: 81) reúne otras características además de la apelación al pueblo y la crítica a las élites, que están presentes en el discurso populista, como puede ser la exaltación de la figura de un líder carismático, y la narrativa de la crisis aunada a la utilización masiva de emociones.

Sin embargo, aunque el discurso populista tiene una serie de características inherentes a su condición política, éste presenta diferencias significativas distinguiendo entre ideologías de derechas o de izquierda. Rydgren (2017: 485), quien considera engañoso considerar a los partidos de extrema derecha surgidos desde la época de los 80 como populistas, sí que cree que muchos de los rasgos definitorios del populismo se asemejan con el discurso ofrecido por esos partidos radicales de derecha contemporáneos en Europa (Rydgren, 2017: 489).

Los populismos de izquierda articulan un discurso que hace énfasis en la igualdad social, la posición anticapitalista y la aproximación en su ideario político a los grupos feministas, LGTBI e inmigrantes (Moriche, 2016: 36). Por el contrario, para los partidos populistas de extrema derecha, el pueblo "se constituye como una comunidad etnonacional que se concibe en términos de identidades culturales" (Roberts, 2017:231) y que hunde sus raíces en la exclusión hacia los inmigrantes, y, en diversos grados, hacia otras minorías étnicas o raciales, que a menudo se manifiesta en xenofobia y racismo (Rydren, 2017: 485) hacia el islam y la población musulmana (Alonso, 2018: 80 y ss) y, por supuesto, que contribuye a crear un ambiente de crispación y antieuropeísmo fuera de la economía neoliberal (Solana, 2009: 3). Asimismo, y como señala Taggart (2004: 273), la derecha populista se identifica como un "corazón sagrado" o "heartland", es decir, se consideran nostálgicos de un pasado ideal a recuperar.

En lo que a coyuntura comunicativa se refiere, algunos autores, tras el nacimiento de internet, "otorgaron a las redes sociales el potencial de reestructurar el poder político en una dirección evidentemente populista" (Engesser et al. 2017: 1113). La idoneidad de plataformas como Twitter han provocado el efecto denominado "populismo 2.0" (Gerbaudo, 2014, citado en Pérez-Curiel, 2020: 177) cuya estrategia reside en el empleo de mensajes que se harán virales en redes gracias a los líderes populistas y que, por supuesto, superan las barreras para acceder a los medios convencionales (Pérez-Curiel, 2020: 177). Aunque autores como Ernst et al. (2017: 12) han llegado a la conclusión de posicionar a Facebook como principal plataforma social por la que los partidos populistas difunden sus mensajes, es innegable asumir que Twitter se ha consolidado como una herramienta clave en la transmisión de comunicación política por su carácter moderno, su conversación directa entre el ciudadano y el político, y ser una fuente de información para los propios periodistas (Rodríguez y Uceda, 2011: 91 y ss).

Así, investigaciones como la que aportan Rivas-de-Roca, García y Bezunartea (2020: 233), donde analizaron la cuenta del líder político de Vox en Twitter durante las elecciones 
de Andalucía en 2018, demostraron que era el candidato con más menciones directas negativas a otras formaciones y líderes, sus tuits estaban dedicados a la organización de eventos y a la movilización de votación y, finalmente, obtenía un gran impacto de interacción en respuestas y tuits. Bracciale y Martella (2017: 1323) demostraron empíricamente que el partido italiano "Liga Norte" empleó en la agenda de Twitter un enfoque comunicativo destinado a personalizar la narrativa política a través del intercambio de emociones y la vida privada de su líder Mateo Salvini, así como a mostrar aspectos de la campaña electoral y la participación de la audiencia. Finalmente, y relacionado con la investigación que nos compete, en el trabajo ya mencionado anteriormente de Pérez- Curiel (2020: 187), se analizó la posible asimilación de agendas entre El País y la cuenta oficial de Twitter de Santiago Abascal, resaltando que en varias ocasiones, los temas planteados por el líder de Vox aparecieron también en el periódico, demostrando una equivalencia y proyección entre la agenda mediática y la del líder del partido.

\section{Preguntas de investigación}

A la luz de lo descrito hasta este punto, nuestro estudio explora la estrategia comunicativa que Vox ha utilizado durante las campañas electorales que tuvieron lugar en 2019, así como el papel que han jugado las televisiones en la creación y consolidación de una imagen pública del propio partido en la arena pública. El auge de esta formación en las elecciones andaluzas generó una gran expectación mediática, lo que favoreció una coyuntura propicia para analizar la cobertura que dan a la política los medios de comunicación, en especial la televisión y la red social Twitter.

El objetivo principal es llevar a cabo una aproximación a la estrategia comunicativa que siguió el partido político Vox, y la cobertura informativa que las televisiones realizaron en torno a la formación de Santiago Abascal, para lograr entender cuáles han sido algunos de los elementos discursivos, políticos y mediáticos, que le han dado la capacidad al partido de consolidarse como tercera fuerza política en el Congreso.

El estudio se compone de tres preguntas; las dos primeras limitadas a la agenda setting, y la tercera a los elementos propios del discurso populista. Estas preguntas son al mismo tiempo las herramientas que nos permitirán comprobar el objetivo general de la investigación

P1: ¿Qué temas relacionados con la formación política han suscitado mayor importancia y cuál ha sido su valoración en la agenda mediática de las televisiones durante ambas campañas?

P2: ¿Los temas ofrecidos por el propio partido en su cuenta oficial de Twitter se han asemejado a los ofrecidos por las televisiones analizadas?

P3: ¿Ha utilizado Vox explícitamente en su discurso los elementos característicos del populismo en su cuenta oficial de Twitter durante las campañas analizadas?

De acuerdo con estas preguntas, las hipótesis de investigación son las siguientes

H1: Los temas introducidos por las televisiones en su agenda atenderán a cuatro bloques claramente diferenciados, distinguiendo entre policy issues, campaign issues, politial issues y personal issues. En concreto, durante las campañas investigadas, se 
espera que las televisiones ofrezcan en mayor medida temas relacionados con las campaign issues. Asimismo, se espera que la valoración que las cadenas realicen sobre la formación de extrema derecha sea evidentemente negativa.

H2: Los temas introducidos por el propio partido en la cuenta de Twitter no se asemejarán a los introducidos por las televisiones, pues el partido ofrecerá cuestiones de política sectorial, es decir policy issues.

H3: VOX construirá en sus mensajes de la cuenta oficial de Twitter los elementos que caracterizan al movimiento populista de extrema derecha.

\section{Metodología}

Los medios seleccionados para llevar a cabo la investigación son dos grandes cadenas televisivas españolas, Televisión Española (TVE) y Telecinco. En el caso de TVE su elección se debe a la condición de cadena pública de referencia en España, así como haber conseguido datos de audiencia que han alcanzado los 11,5 puntos del share, el día 6 de noviembre de 2019. Además, la televisión pública presenta un estilo formal, correcto y plural, pero tal y como indican Pérez et al. (2018: 1085), el tratamiento de la información política e institucional refleja que TVE tiene una línea progubernamental. En el caso de Telecinco, su elección se debe a que ha sido, durante el periodo analizado, la cadena privada con mayores audiencias en los informativos nocturnos, llegando a alcanzar los 2.385.000 de espectadores. Asimismo, para las hipótesis 3 y 4 se escogió la red social Twitter, no sólo por su condición irrefutable de herramienta vicaria en las estrategias de comunicación de los partidos políticos, sino porque el uso de redes sociales ha demostrado la capacidad que otorgan a los partidos en su ímpetu por construir una agenda pública y temática (Rivas et al, 2020: 228; López y Valera, 2017).

La muestra inicial está compuesta por un corpus de 56 noticias, referidas exclusivamente a mostrar información relativa al partido político Vox, de los informativos nocturnos durante la campaña electoral: 25 emitidas por TVE y 31 por Telecinco. Las noticias se seleccionaron a través de la versión web de Telecinco y TVE. Asimismo, se visualizaron los informativos nocturnos de forma completa puesto que, a diferencia de los del mediodía, estos cuentan con un mayor abanico de noticias. Para el análisis de Twitter, con el fin de investigar directamente los mensajes publicados por el partido, la muestra se comprende por un total de 264 tuits originales (escritos directamente por el usuario) recabados a mano en la búsqueda avanzada de la red social. En el caso de los tweets, se realizó una tabla de Excel en la que se ordenaron cronológicamente según el día de su publicación, el tuit en cuestión y el enlace directo a la plataforma en internet.

Como se puede comprobar, la muestra tanto de las noticias como de los tuits es relativamente pequeña, lo que significa que los resultados obtenidos deben ser tomados con precaución y ser representativos exclusivamente al periodo analizado.

El periodo escogido abarca un total de 23 días, del 12 de abril de 2019 hasta el 26 de ese mismo mes (ambos inclusive), y del 1 al 8 de noviembre de 2019. Esto supone analizar las dos campañas electorales correspondientes a las elecciones generales de 2019, momento en el que Vox se incorpora de pleno en el Congreso de los Diputados.

El contraste de las hipótesis anteriormente planteadas se realizará mediante el análisis de contenido cuantitativo utilizando la herramienta SPSS para el procesamiento de los datos, complementado con un análisis de tipo cualitativo. La parte cuantitativa permiti- 
rá obtener unos resultados puramente demostrativos, mientras que la parte cualitativa ofrecerá conclusiones con un peso más descriptivo (Gómez et al. 2018: 198).

Este análisis se centró en las siguientes variables:

Identificación: variables cuyo único objetivo era la ubicación de la noticia en cada informativo o tuit que hacía referencia a la muestra. Se ha categorizado según el tipo de publicación; cadena o Twitter, si la cadena era TVE o Telecinco y la fecha de la información.

Enfoque temático y la relevancia de la noticia/ tuit: La categorización de estas variables (véase anexo 1) es la aportada por López y Valera (2017) en su investigación sobre la campaña de las elecciones generales españolas en 2015 en Twitter. Una categorización que, a su vez, seguía la tipología propuesta por Patterson (1980). Para este ítem se ha optado por agrupar en su categorización los indicadores; "impuestos y recortes"; "deuda pública, balanzas fiscales y vivienda" y "manipulación informativa pública y privada". A su vez se ha obviado el indicador denominado "temas ajenos a la campaña electoral". Esta reducción ha permitido medir de manera más precisa las piezas informativas analizadas. Respecto a la categorización final, se ha dividido entre; "political issues", "cuestiones concernientes a la esfera ideológica de los partidos y candidatos, alianzas entre partidos, relaciones con la sociedad civil y los poderes fácticos"; "policy issues", cuestiones de política sectorial como la educación, la sanidad, etc.: "personal issues", cuestiones concernientes la vida privada de los candidatos, y, finalmente, "campaign issues" a cuestiones relacionadas con el devenir de la campaña, como los sondeos, candidaturas o actos de campaña (López y Valera, 2017: 29).

Valoración sobre el protagonista: Se quería comprobar si la noticia era negativa, positiva o neutra para el protagonista. Cuánto duraba en minutos, si aparecía o no en sumario, si la noticia relacionada con Vox aparecía antes que otras formaciones políticas, y si contenía recursos audiovisuales; distinguiendo entre audio y video, solo audio, solo video y gráficos o esquemas. Esta categorización se obtuvo del diseño propuesto por Humanes (2001: 4) sobre el encuadre mediático de la realidad social. En el caso de nuestra investigación, se optó por obviar los indicadores relacionados con el tratamiento y con los personajes que Humanes aplica en su metodología, pues en nuestra ficha de análisis aplicamos la categorización que mide exclusivamente la importancia que se concede a unos asuntos frente a otros que suscitan un menor interés durante las campañas electorales. En cuanto a la valoración de la noticia, categoría que se relaciona con el segundo nivel de la agenda setting (Aruguete, 2009: 27), se estableció como negativa cuando el suceso o sus consecuencias fueran juzgadas como negativas por el periodista en relación a la formación verde. La valoración era positiva cuando el suceso o sus consecuencias fuesen juzgadas como positivas para Vox, y, finalmente, la valoración era neutra cuando no existía valoración alguna.

Elementos del discurso populista: la aportación metodológica de Alonso (2018) permitirá afirmar si el discurso de Vox es populista o no, mediante la publicación en Twitter de mensajes relativos al pueblo como constructo social, así como el tipo de término utilizado para referirse al mismo; si la formación critica a las élites y el actor al que va dirigida esa crítica; si critica a otros colectivos; si hace referencias a diversas crisis y el tipo de crisis a la que apela; si el partido es euroescéptico, y finalmente, si ensalza la figura de su líder, Santiago Abascal. Sin embargo, para este ítem final se optó también 
por no contar con todos los indicadores que la tesis de Alonso (2018) ofrecía en su metodología, pues como se muestra en el Anexo 1, se reagruparon estas categorías de tal forma que nos permitió reunir mejor los acontecimientos principales de cada unidad de análisis. Además, se complementó la categorización añadiendo "crisis provocada por la inmigración"; "la seguridad o terrorismo"; "los asuntos externos" y el "modelo territorial español", teniendo en cuenta como referencia el trabajo realizado por Pérez (2020) sobre la retórica de los partidos populistas de extrema derecha en Twitter.

\section{Resultados}

\subsection{Resultados de los informativos analizados}

Los resultados, que se han estructurado siguiendo las preguntas de investigación: un apartado con el análisis de las televisiones y otro con los datos ofrecidos por la cuenta oficial del partido en Twitter han demostrado que, en términos televisivos, existen diferencias notables en cuanto al número de noticias emitidas por las cadenas analizadas durante el periodo investigado. Telecinco ofreció, en términos generales, más información relativa a Vox que la televisión pública. Así, la cadena privada sumó un total de 31 noticias en ambas campañas; 6 más que TVE. De esas 31 noticias, 21 se emitieron en la campaña del 28 de abril y 10 noticias durante los ocho días que duró la campaña del 10 de noviembre, lo que supuso reducir el número de informaciones sobre la formación cuando ya formaba parte del Congreso. TVE, en cambio, muestra unos resultados diferentes, pues si la cadena pública ofreció 7 noticias sobre VOX en la primera campaña electoral, la cifra se incrementó en la segunda campaña analizada, alcanzando las 18 noticias.

\subsubsection{Valoración de la cadena sobre el partido político}

Aunque la investigación nos haya permitido verificar que no existen diferencias abruptas en cuanto al número de noticias emitidas por ambas cadenas, lo cierto es que dependiendo de la televisión analizada y el momento estudiado se pueden encontrar variaciones de la valoración que se ha ofrecido a la audiencia sobre Vox. Así, tanto en la campaña de 28 de abril como en la del 10 de noviembre, en TVE, el 56\% de las noticias emitidas tenían un carácter neutro para el partido político, el $24 \%$ eran positivas, y solo un $20 \%$

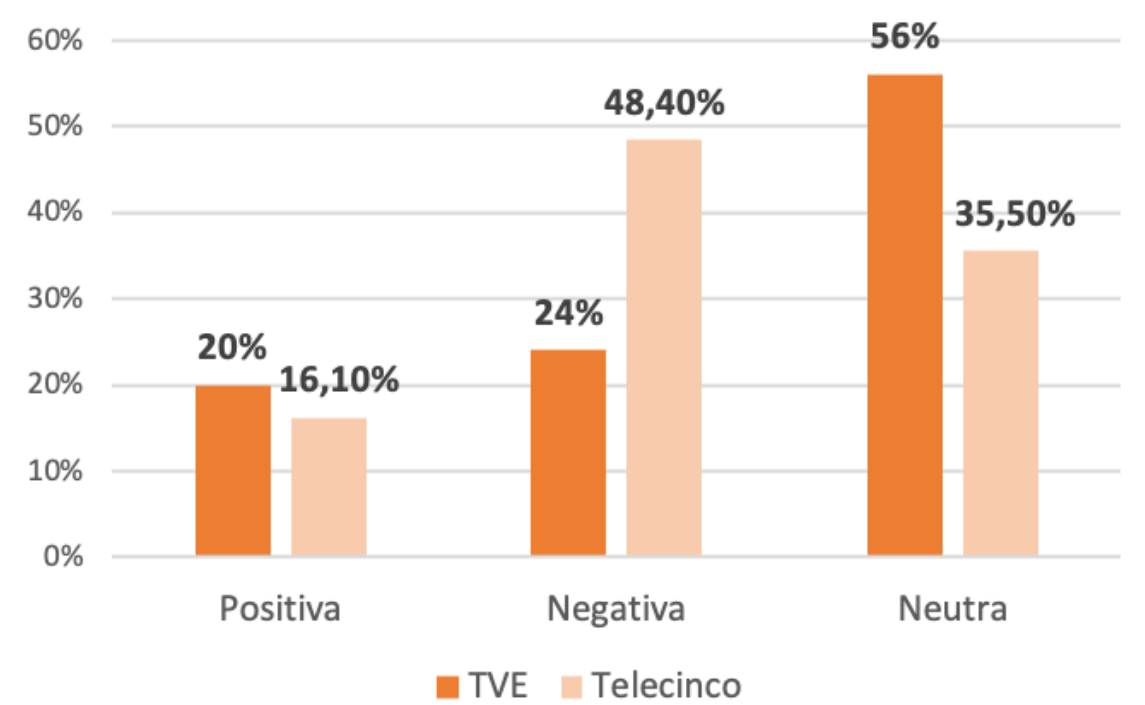
de las noticias contaban con aspectos negativos para Vox. Por el contrario, Telecinco ofrecía en el $48,40 \%$ de noticias aspectos de carácter positivo, el $35,50 \%$ de ocasiones el carácter era neutro, y únicamente el $7,60 \%$ de las veces la noticia presentaba aspectos negativos.

Gráfica 1. Valoración de la noticia. Elaboración propia 
En las elecciones del 28 de abril, la televisión pública ofrecía noticias mayoritariamente neutras $(57,10 \%)$, y un porcentaje muy bajo de noticias positivas sobre el partido Vox $(14,30 \%)$. Pero estos porcentajes se modificaron durante el segundo periodo analizado, viéndose incrementadas las noticias con valoración positiva hasta el $27,80 \%$ de los casos, y reduciendo las que presentaban un carácter negativo sobre Vox (16,70\%). En el caso de Telecinco, en el segundo periodo electoral el porcentaje de noticias con carácter positivo para el partido se incrementó un 18\%, disminuyendo así tanto las noticias negativas al 10\%, como las neutras, pasando del 38\% al $30 \%$.

\subsubsection{Categorías temáticas de la agenda mediática}

En cuanto a la categoría que cuenta con un amplio porcentaje en los informativos estudiados de ambas cadenas, son los political issues los que obtienen la mayor representación. De hecho, la televisión pública utilizaba esta categoría temática en más del $50 \%$ de las noticias emitidas durante ambas campañas electorales, un porcentaje que no dista del de Telecinco; cadena que obtiene más del 30\% de información dedicada, precisamente, a esta misma categoría.

También podemos destacar un amplio uso, en ambas cadenas, de los temas relacionados con la campaña (campaign issues). De hecho, los informativos de la cadena privada son los que más han introducido en su noticiario esta temática (39,10\%). Sin embargo, es la categoría dedicada a hablar sobre cuestiones de política sectorial (policy issues), la que obtiene un bajo porcentaje en ambas cadenas, pues solo Telecinco supera el $20 \%$ de noticias, mientras que TVE no supera el $10 \%$. Cabe destacar, finalmente, que las noticias referidas a las anécdotas personales de los candidatos sólo se encuentran presentes en los informativos de Telecinco, pues esta cadena ha tratado de informar sobre los rasgos, las cualidades y aficiones personales de algunos de los candidatos de Vox.

\subsubsection{Relevancia de la noticia según su posición, duración y recursos utilizados en el informativo}

La aparición de noticias en el sumario por parte de las cadenas estudiadas es claramente bastante. Así, en ambas campañas electorales, TVE sólo cuenta con un total de $44 \%$ de noticias que aparecieron en sumario, mientras que Telecinco lo hace únicamente en el $25,80 \%$ de las ocasiones. Estos porcentajes varían según el momento analizado, y en el caso de la televisión pública, durante la primera campaña electoral las noticias sobre

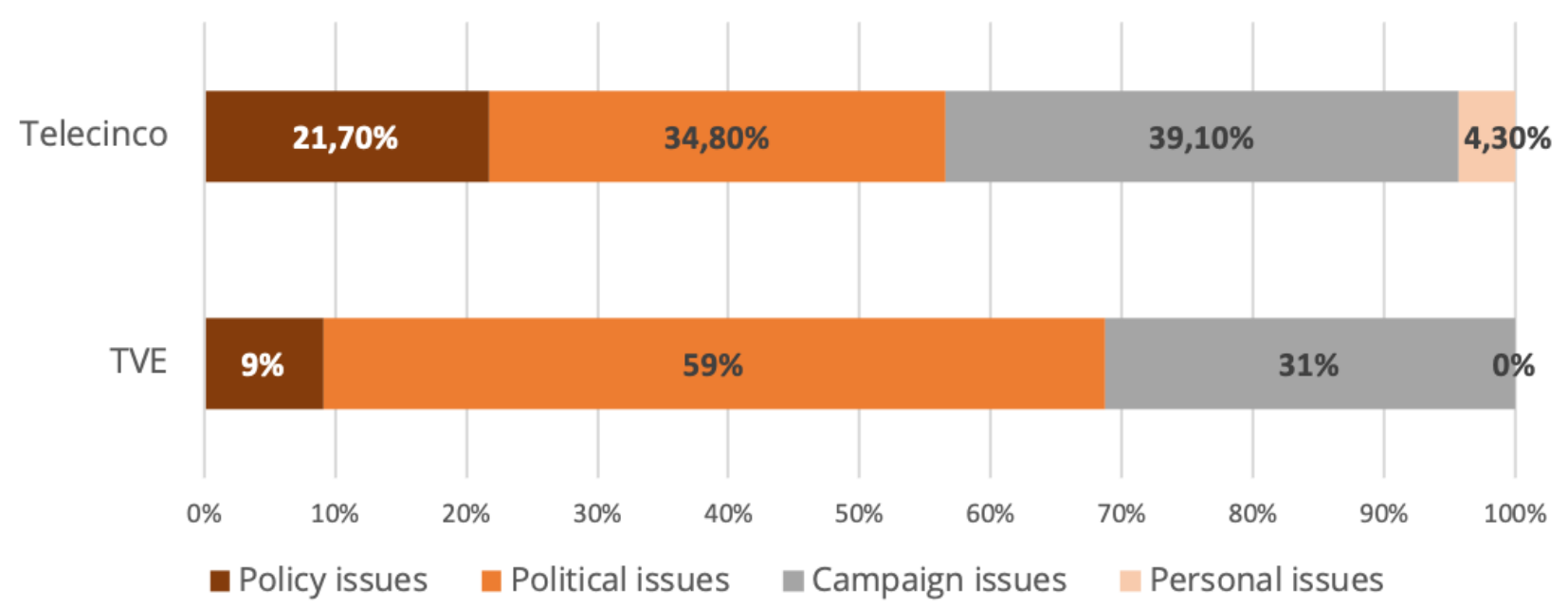

Gráfica 2. Categoría temática más utilizada por las cadenas. Fuente: elaboración propia 
Vox en sumario no llegaban al 30\%, mientras que en el segundo periodo alcanzó el $50 \%$. Del mismo modo, Telecinco, incrementó en la campaña del 10 de noviembre de 2019 las noticias que aparecían en sumario hasta el 40\%.

Tabla 1. Posición que ocupa la noticia en el informativo. Fuente: elaboración propia

\begin{tabular}{|l|l|l|}
\hline Posición de la noticia en el informativo & Telecinco \\
\hline $\begin{array}{l}\text { Aparece en el sumario, tanto en el primer como en el segundo } \\
\text { periodo analizado }\end{array}$ & $44 \%$ & $25,80 \%$ \\
\hline $\begin{array}{l}\text { No aparece en el sumario, tanto en el primer como en el } \\
\text { segundo periodo analizado }\end{array}$ & $56 \%$ & $74,20 \%$ \\
\hline $\begin{array}{l}\text { Aparece en el sumario, en los informativos analizados de la } \\
\text { campaña electoral del 28 de abril }\end{array}$ & $28,20 \%$ & $19 \%$ \\
\hline $\begin{array}{l}\text { No aparece en el sumario, en los informativos analizados de la } \\
\text { campaña electoral del 28 de abril }\end{array}$ & $71,40 \%$ & $81 \%$ \\
\hline $\begin{array}{l}\text { Aparece en el sumario, en los informativos analizados de la } \\
\text { campaña electoral del 10 de noviembre }\end{array}$ & $50 \%$ & $40 \%$ \\
\hline $\begin{array}{l}\text { No aparece en el sumario, en los informativos analizados de la } \\
\text { campaña electoral del 10 de noviembre }\end{array}$ & $50 \%$ & $60 \%$ \\
\hline
\end{tabular}

De la duración que cada informativo ha dedicado a mostrar información sobre la formación política, los resultados obtenidos demuestran que las dos cadenas han ofrecido un trato similar. Sin embargo, lo realmente significativo de la investigación se encuentra dependiendo del periodo electoral ha analizado, pues llama la atención que Telecinco, siendo la emisora que más noticias ha ofrecido a la audiencia sobre Vox, dedicó un menor número de minutos a la información política en el segundo periodo investigado. Esta situación difiere de la ofrecida por TVE, ya que, si en la campaña electoral del 28 de abril no mostró ninguna noticia sobre el partido que superase el minuto y medio de duración, en la segunda campaña, el 33,30\% de las noticias analizadas obtuvieron más de dos minutos en los informativos.

Tabla 2. Duración de las noticias dedicadas a hablar sobre Vox. Fuente: elaboración propia

\begin{tabular}{|l|l|l|}
\hline Duración de las noticias & TVE & Telecinco \\
\hline De 1 a 30 segundos & $44 \%$ & $51,60 \%$ \\
\hline De 30 segundos a 1 minuto & $24 \%$ & $25,80 \%$ \\
\hline De 1 minuto y 1 minuto y medio & $8 \%$ & $9,70 \%$ \\
\hline Más de dos minutos & $24 \%$ & $12,9 \%$ \\
\hline
\end{tabular}




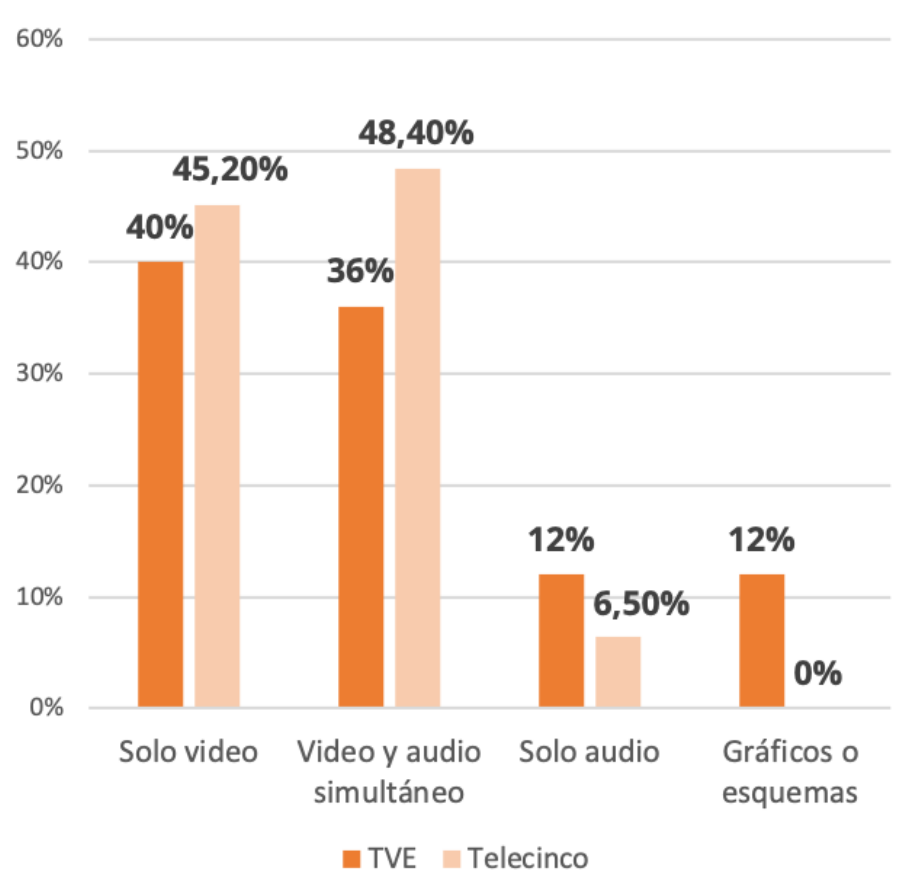

En cuanto a los resultados obtenidos sobre los recursos audiovisuales que han utilizado las cadenas, se ha comprobado que existen discrepancias significativas. TVE utiliza video y audio simultáneo en el $36 \%$ de las ocasiones, mientras que el porcentaje de Telecinco alcanza casi el 50\%. A su vez, la televisión pública utiliza solo video el $40 \%$ de las veces, y Telecinco aumenta en $5 \%$ este resultado. Además, Telecinco no utiliza en ningún momento gráficos o esquemas para emitir información sobre Vox, mientras que TVE lo hace el $12 \%$ de las ocasiones.

Gráfica 3. Recursos utilizados por las cadenas. Fuente: elaboración propia

\subsection{Resultados de los tuits de Vox en el estudio de la agenda del partido}

Se analizó la cuenta oficial de Twitter del partido para comprobar la agenda temática que VOX ha establecido en la opinión pública. Se ha comprobado que el partido ofrece en su cuenta oficial, de manera casi equitativa, tuits relacionados con la confrontación electoral, cuestiones de política sectorial y asuntos relacionados con el devenir de la campaña. El partido también publica tuits en los que se indica el lugar donde tendrán lugar los eventos de campaña, política sobre inmigración, el independentismo catalán, los impuestos y el empleo. Los temas relacionados con la sanidad, la educación o el medio ambiente también se han encontrado de manera reiterativa en Twitter, pero no como para establecerlos de herramientas propagandísticas en su estrategia comunicativa.

Tabla 3. Categoría temática utilizada por VOX en su cuenta oficial de Twitter. Fuente: elaboración propia

Tipo de categoría temática utilizada

\begin{tabular}{|c|c|}
\hline Policy issues & $29,90 \%$ \\
\hline Campaign issues & $34 \%$ \\
\hline Political issues & $30,50 \%$ \\
\hline Personal issues & $5,50 \%$ \\
\hline
\end{tabular}

\subsection{Resultados de las características del populismo en la cuenta oficial de VOX_es}

El análisis numérico en Twitter del partido ha podido constatar, gracias a la metodología aportada por Alonso (2018), el alto grado de populismo que existe en los mensajes difundidos en la red social por parte del partido de extrema derecha. La muestra ha permitido corroborar que el partido ha empleado la mayoría de las características inherentes al populismo. 


\subsubsection{La apelación al pueblo en los tuits de Vox}

La gráfica 4 revela el porcentaje total de tuits que el partido ha publicado en su red social, apelando o no al pueblo. En esta línea, y como se puede observar, la variación porcentual es casi mínima, pues Vox ha apelado al pueblo en el $43,90 \%$ de las ocasiones, mientras que no lo ha hecho el $56,10 \%$ de los casos. Pero más allá de esta diferencia de porcentajes, se demuestra que el partido ha usado con frecuencia la apelación al pueblo como estrategia comunicativa en sus mensajes de Twitter.

Gráfica 4. Apelación al pueblo en los tuits de VOX. Fuente: elaboración propia

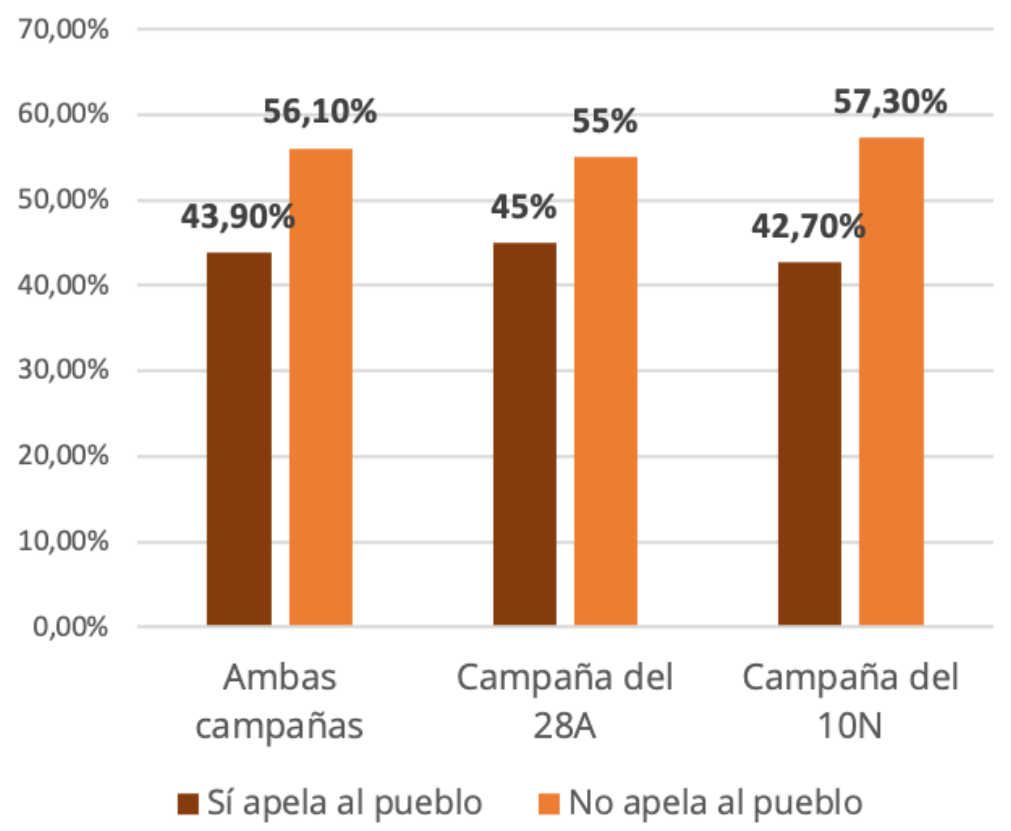

Los datos demuestran una clara homogeneidad en cuanto a la terminología aplicada por el partido para referirse al pueblo; "La España Viva" y "Los españoles" ha sido la terminología imperante en las campañas electorales analizadas. Sin embargo, términos como "autónomos", "la clase media", la "familia", "el mundo rural" y "España rural son utilizados por Vox en su afán por construir una idea común de pueblo.

Imagen 1. Apelación al pueblo con el hashtag \#EspañaViva en la cuenta oficial de Vox_es. Fuente: Twitter.com

$$
\text { VOx vox }=8
$$

No te pierdas la historia de Miguel Ángel, uno de los millones de currantes de la \#EspañaViva

En VOX siempre estaremos del lado de la España que madruga, se esfuerza, contribuye y lo único que quiere es vivir en libertad.

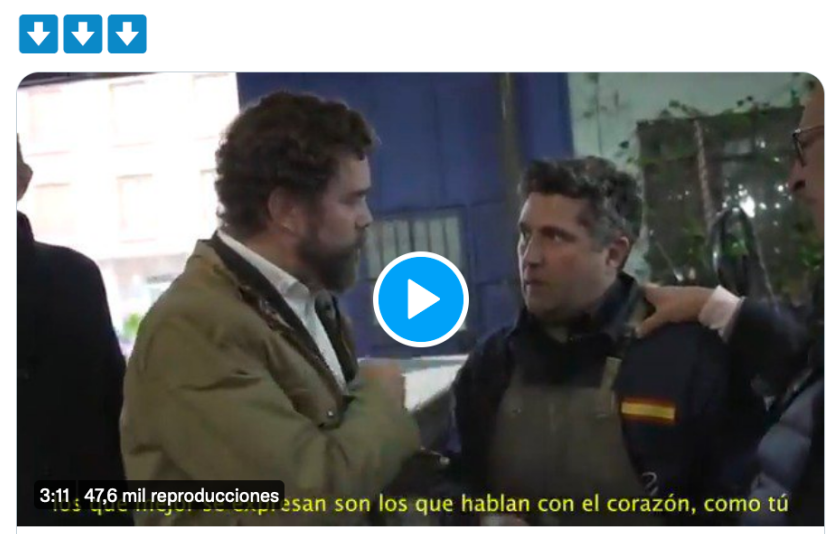

Iván Espinosa en una Fragua de Ciudad Real
VOx $\begin{aligned} & \text { vox }=0 \\ & \text { @voxes }\end{aligned}$

* La \#EspañaViva se vuelca en Asturias para apoyar a VOX y @Santi_ABASCAL en el primer acto de campaña.

Ya queda menos para que este 28 de abril hagamos historia 5

Más de 2.000 personas en el interior del Palacio de Congresos de Oviedo y cientos sin poder entrar

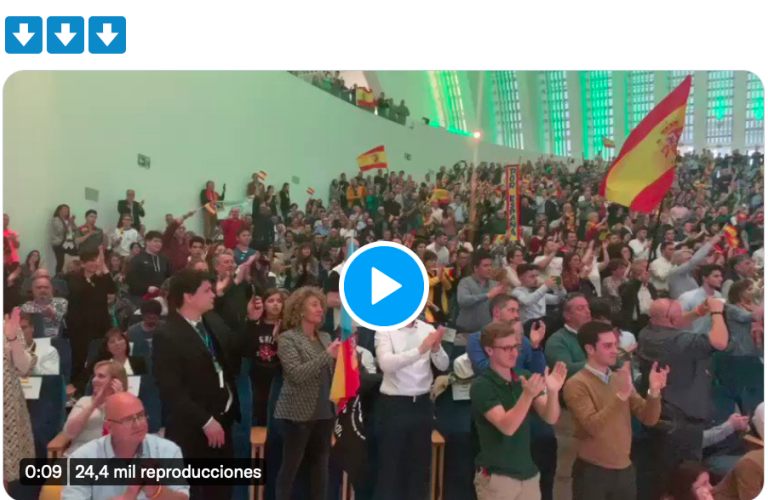




\subsubsection{La crítica a las élites}

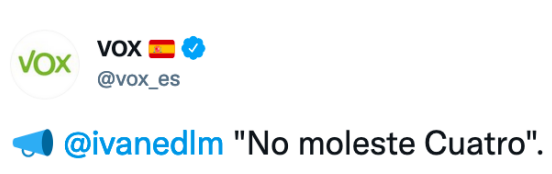

El 28 de abril tu voto a VOX será el mayor zasca a los medios progres

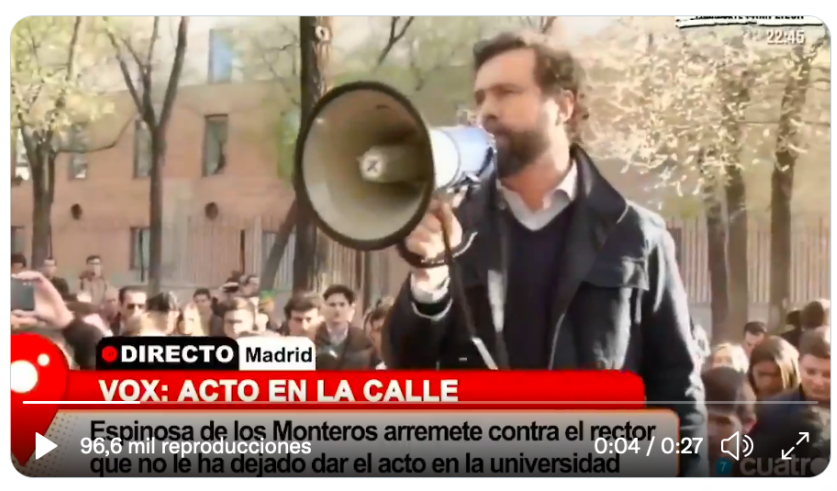

10:59 a. m. · 12 abr. 2019 - Twitter for Android

Imagen 2. Crítica a la cadena Cuatro, alegando que se trata de un "medio progre".

Fuente: Twitter.com
Desde una perspectiva claramente antielitista, Vox ataca a diversos adversarios. Entre estas élites se pueden encontrar los políticos $(58,60 \%$ de ocasiones) tanto de derechas como de izquierdas, pues Vox trata de culpabilizar a todos los partidos (PSOE, PP, Podemos y Ciudadanos) de la crisis económica en la que España y "Los españoles" llevan inmersos. Asimismo, también presentan un alto porcentaje las críticas a las élites mediáticas, $\quad(20,70 \%)$, mostrándose claramente beligerante con Cuatro, Atresmedia, TVE y El Español. Además, las élites económicas $(4,60 \%)$, las instituciones $(6,90 \%)$, el sistema judicial $(3,40 \%)$ y el gobierno (4\%) son las diversas tipologías de élite que la formación de derechas ha tratado de criticar en la construcción de su mensaje.

\subsubsection{La exclusión de otros colectivos y el euroescepticismo}

Uno de los rasgos característicos de la comunicación del partido de Santiago Abascal, y que no comparte con otros partidos de extrema derecha como podría ser el Frente Nacional Francés, es la falta de crítica hacia otros colectivos. Sólo 28 tuits han sido publicados en la red social para increpar a otros colectivos. Los antitaurinos, el colectivo animalista, el feminista y los okupas, son algunos de los ejemplos que Vox considera "enemigos de España". Sin embargo, en un contexto español marcado por el conflicto independentista, la formación verde critica a colectivos como los CDR (Comité de Defensa de la República).

Además, el partido no apuesta en ninguna de las campañas analizadas por ofrecer una perspectiva euroescéptica en Twitter. Sólo en dos de los 264 tuits analizados han criticado a Europa como institución. Por consiguiente, el discurso de Vox en esta red social no cuenta con críticas a otros colectivos ni con un euroescepticismo exacerbado.

\subsubsection{Referencias a la crisis}

El partido lanza mensajes generando entre la opinión pública una sensación de crisis duradera provocada por los partidos que llevan gobernando en España desde el comienzo de la democracia. De los 264 tuits analizados, 142 hacen referencia a la existencia de un tipo de crisis, siendo las elecciones del 10 de noviembre el momento en el que el partido hizo hincapié en usar esta retórica en su estrategia comunicativa. Así, como se observa en la gráfica 5.0, la existencia de una crisis social y política obtiene una relevancia especial en la primera campaña electoral, mientras que, en el segundo periodo analizado, es el conflicto catalán el que se sitúa como punta de lanza en el discurso populista del partido. 


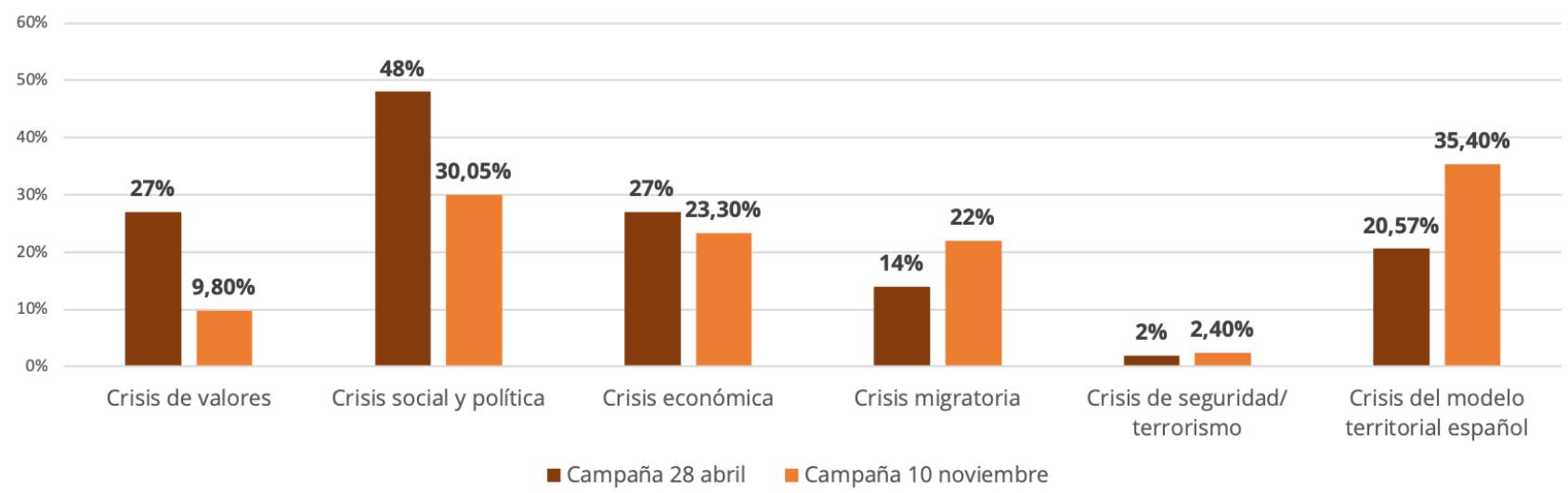

Gráfico 5. Tipos de crisis enmarcadas por Vox en su discurso de Twitter. Fuente: elaboración propia

La posición del partido en términos de crisis migratoria y económica también es considerable. VOX intenta relacionar la inmigración procedente de países de religión musulmana conel terrorismo, presuponiendo quela inmigración masiva generaviolencia

$$
\text { vox } \begin{aligned}
& \text { vox }=0 \\
& \text { @vox_es }
\end{aligned}
$$

Ø̋ivanedlm propone la cadena perpetua para los delitos más graves, frenar la inmigración masiva y solucionar el problema de inseguridad en nuestras calles a causa de los menas.

\section{I \#Debatea7RTVE}

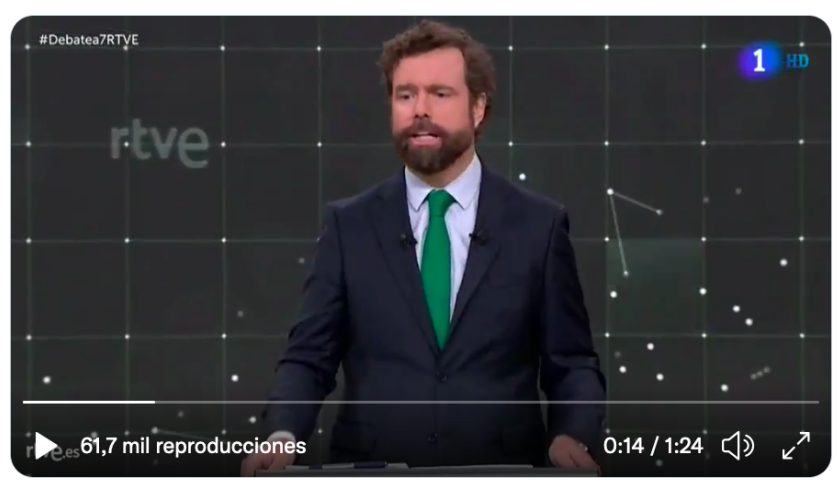

11:33 p. m. $\cdot 1$ nov. $2019 \cdot$ Twitter Ads y pérdidas económicas para todos los españoles. En especial, VOX culpabiliza a los menores inmigrantes (MENAS) de la inseguridad y el caos en España. El partido de extrema derecha realiza un constructo de crisis política, económica y migratoria que pretende crear un ambiente de crispación y polarización entre la sociedad, resaltando la necesidad de tomar medidas excepcionales para poder solucionar problemas que en la mayoría de las ocasiones son inventados por ellos mismos.

Imagen 3: Iván Espinosa durante el debate en TVE sugiriendo la cadena perpetua ante la crisis de seguridad provocada por Ios MENA. Fuente: Twitter.com

\subsubsection{El ensalzamiento de la figura del líder y la apelación al pueblo mediante el uso de emociones}

Santiago Abascal, líder de Vox, es ensalzado por el partido durante el discurso utilizado en ambas campañas electorales. Abascal es representado como un líder valiente y decidido a "acabar con la dictadura progresista", se le llega a comparar con una estrella de popy sus cualidades son destacadas, mostrando su faceta más personal y emocional.

Sin embargo, la estrategia que utiliza el partido para proyectar una imagen potente de su líder varía según el momento analizado. Así, en la campaña del 28 de abril, 53 de los 140 tuits se publicaban para elogiar la figura de Abascal, mientras que en el segundo periodo analizado sólo el 6,50\% de la muestra se centró en el ensalzamiento del presidente del partido, dando más voz a los demás miembros del partido.

Finalmente, los datos obtenidos demuestran que la formación política ha hecho un 
uso generalizado de las emociones en el discurso construido desde la cuenta oficial de Twitter. "Cariño"; "amor por mi patria"; "defender la libertad" o "las personas que más lo necesitan", son algunos de los términos utilizados para apelar directamente al pueblo mediante el uso de las emociones. Antes que la razón, vOX ha optado por realizar una gestión comunicativa centrada en transmitir emociones para "calar" más entre la población española.

$$
\text { VOx } \begin{aligned}
& \text { vox }=\$ \\
& \text { @vox es }
\end{aligned}
$$

@Santi_ABASCAL, de subirse a un banco en la calle a estrella del pop en Sevilla elmundo.es/espana /2019/04... vía @alvaro7carvajal para @elmundoes

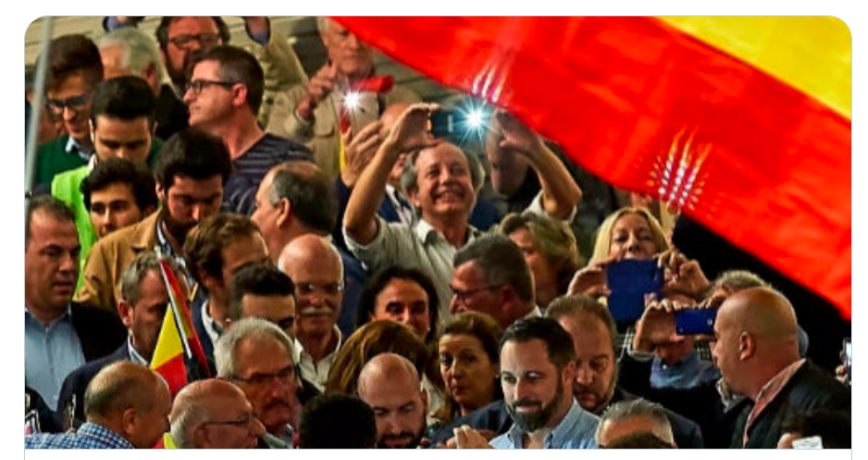

Santiago Abascal: de subirse a un banco en la calle a estrella del pop en Sevilla Hay pocos lugares que expliquen mejor la historia de Vox que Sevilla. Una ciudad convertida en si misma en metáfora para Santiago Abascal y para la formación ... $\mathcal{S}$ elmundo.es

1:13 a. m. $\cdot 25$ abr. $2019 \cdot$ Twitter for Android
VOX $\underset{\substack{\text { vox } \\ \text { @vos es }}}{2}$

@Santi_ABASCAL recibido en el Palacio de Euskalduna de Bilbao entre vítores y gritos de "ipresidente!, ipresidente!"

Este 28 de abril la \#EspañaViva también hará historia en las plazas más complicadas okdiario.com /espana/abascal... vía @okdiario

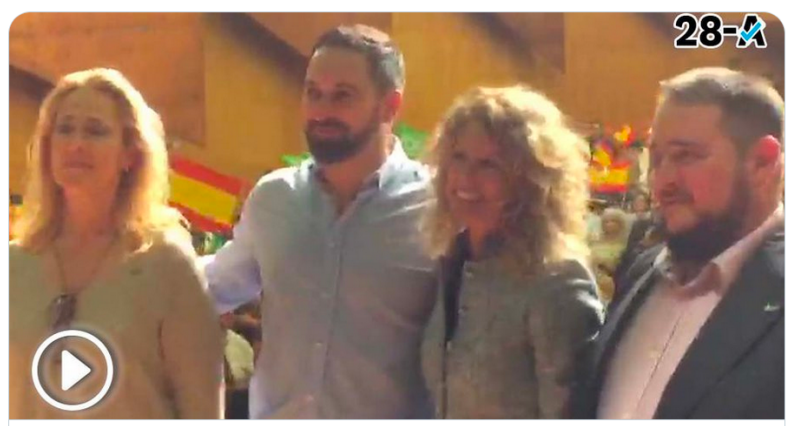

Santiago Abascal recibido en Bilbao entre vítores y gritos de "ipresidente!, ipres... Santiago Abascal ha entrado en el Palacio Euskalduna recibido por sus simpatizantes entre vitores y gritos de "ipresidente! ipresidente!". Sokdiario.com

11:25 p. m. $\cdot 13$ abr. $2019 \cdot$ Twitter for Android

Imagen 4: Ensalzamiento de la figura de Santiago Abascal durante la campaña del 28 de abril. Fuente: Twitter.com

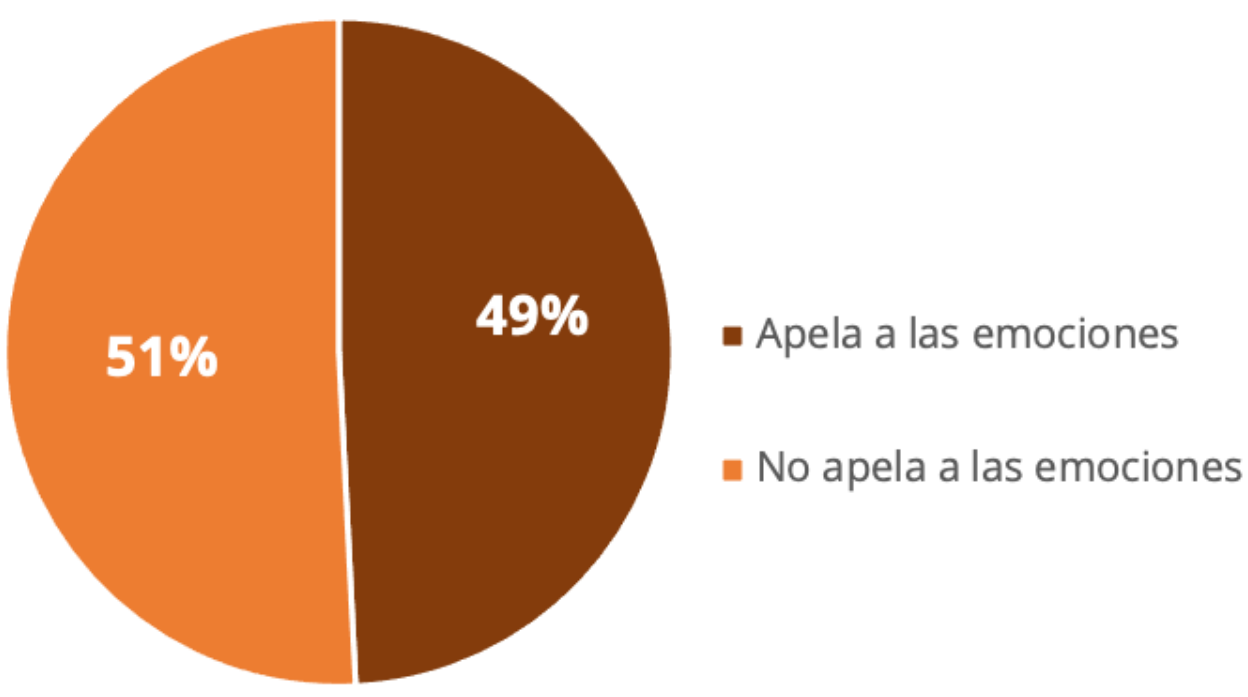

Gráfica 6. Porcentaje apelación a las emociones en los tuits de VOX. Fuente: elaboración propia 


\section{Discusión y conclusiones}

Comprobar la estrategia comunicativa que Vox ha utilizado para llegar a sus votantes y determinar qué visibilidad habían ofrecido las televisiones a la opinión pública sobre el propio partido, con el fin de comprender con qué herramientas comunicativas un partido de extrema derecha había conseguido consolidarse como tercera fuerza política en España, era el objeto de estudio de esta investigación.

En cuanto a los temas ( $\mathrm{H} 1)$ que las televisiones han prestado mayor atención en su agenda mediática, en contra de lo esperado, no se han mostrado asuntos relacionados con el devenir de la campaña (Campaign issues). Telecinco ha ofrecido noticias concernientes a la esfera más abstracta de la confrontación electoral, mientras que las noticias sectoriales y relacionadas con la vida de los candidatos apenas superan el $26 \%$. Por el contrario, la televisión pública ha emitido noticias mayoritariamente de confrontación electoral, dejando en un segundo plano las de carácter sectorial y sin haber mostrado ninguna relacionada con los aspectos privados de los candidatos.

Además, para conocer qué tratamiento han ofrecido las dos televisiones sobre la formación, ha sido fundamental la aplicación metodológica propuesta por Humanes (2001: 4). Ésta, nos ha permitido comprobar la relevancia que la cadena ofrece sobre el partido analizado. Así, Telecinco apenas ha introducido información sobre Vox en el sumario, pero llama la atención que la segunda campaña electoral supuso aumentar en $20 \%$ estas noticias. En TVE, la situación es similar, pues si en la primera campaña electoral, las noticias relacionadas con el partido solo aparecieron en el sumario un $28,20 \%$ de las ocasiones, la segunda campaña el porcentaje aumentó hasta el 50\%. Es bastante probable que esta práctica televisiva se deba al hecho de que las televisiones se vieran constreñidas a incluir más información del partido en sus informativos, gracias en gran medida, a la representación parlamentaria que éste obtuvo en las elecciones del 28 de abril.

Respecto a la valoración que las cadenas hacen de las noticias en las que aparece la formación política, ésta varía según la campaña y la televisión investigada. De esta forma, la televisión pública, bajo su condición de emisora pluralista e imparcial (Humanes et al. 2013), ha ofrecido en un primer periodo electoral una valoración cargada de negatividad, mientras que en términos generales, en ambos periodos, el tono neutro de las noticias ha sido imperante en sus informativos. En el caso de Telecinco, aunque redujo el número de noticias dedicadas a la información del partido verde, es cierto que en ambas campañas la valoración que se ofrece a la ciudadanía es evidentemente positiva.

En el análisis de la cuenta oficial de Twitter (P2), los resultados permitieron hacer una comparación entre la agenda mediática de las televisiones y la agenda del partido, además de poder comprobar qué temas ha utilizado en su estrategia comunicativa según la tipología ofrecida por Patterson (1980). En contra de lo esperado, Vox obtiene un reparto equitativo en la construcción de su discurso, pues a nivel temático, no ha concentrado la atención en un solo tipo de asuntos, sino que centra su discurso tanto en una visión sobre cuestiones de política sectorial, como de confrontación electoral y de cuestiones relacionadas con el devenir de la campaña, además de incluir aspectos personales y de la vida privada del líder, Santiago Abascal. Aunque la agenda del partido no se configure en torno a un tema central, la coyuntura descrita permite apreciar una 
indudable similitud con las estrategias empleadas por la Liga Norte en Italia, y como comprobaron Bracciale y Martella (2017: 1323), Vox también ha constituido su agenda parar mostrar aspectos de la campaña electoral, personalizar el discurso alrededor de la figura y vida privada del líder, y, por supuesto, para hacer referencia a ciudadanos corrientes.

Los votantes "suelen basar su decisión de voto en la información proveniente de los medios" e históricamente, los candidatos han jugado un rol activo en el proceso de agenda, intentando transmitir el programa y las cualidades del partido a través de los medios masivos (Aruguete, 2017: 46). El análisis de contenido ha puesto de manifiesto que no existe una asimilación de agendas entre los medios estudiados y el partido político. Esto significa que los temas que han mostrado las televisiones durante las campañas electorales tienen poco que ver con la campaña desde la cuenta oficial del partido (López y Valera, 2017: 34). La cuestión subyacente, sería determinar "en qué medidas las preocupaciones que conciernen a los ciudadanos están determinadas por la agenda mediática" (López y Valera, 2017: 33) y, por supuesto, en sintonía con esta mirada, comprobar si efectivamente los partidos políticos, a raíz del crecimiento de redes microblogging, pretenden introducir sus temas en los medios tradicionales.

Teniendo en cuenta que el análisis de las cadenas se ha llevado a cabo exclusivamente en dos de la gran variedad de emisoras existentes en el mapa mediático español, y que se ha estudiado exclusivamente la cuenta oficial del partido en Twitter y no en otras plataformas sociales, los resultados sólo pueden extrapolarse a estos medios. Aún así, los datos han resaltado como medios tradicionales y la cuenta oficial de Vox han ofrecido a la opinión pública un discurso totalmente diferente en torno a la información relativa al propio partido. Sin embargo, esto no ha sido óbice para que en los temas que se han abordado con especial relevancia a nivel social y mediático, ambos actores hayan compartido la misma información. Más allá del posible efecto que esto haya suscitado en la decisión de voto de los individuos, queda claro que ha sido el propio partido el que ha creado sus marcos discursivos en Twitter, haciendo de esta red social su principal medio de transmisión de información, obviando de manera encorada a la televisión.

En último lugar, se ha demostrado que el partido es claramente populista (P3). En su mensaje se han codificado la mayoría de los elementos que hacen alusión al populismo, utilizando casi de manera radical un discurso plenamente ideológico. Palabras como "La España Viva", o "Los Españoles" supone construir una ideología que sostiene "que los Estados deberían ser habitados exclusivamente por miembros del grupo nativo ("la nación") y que los elementos no-nativos, tanto personas como ideas, son fundamentalmente una amenaza para un Estado-nación homogéneo" (Mudde, 2007: 19), rechazando al inmigrante y, especialmente al islam y la población musulmana (Vázquez y Campos, 2020: 68). El partido ha disertado sobre la clase política y mediática, exponiendo que tanto la derecha como la izquierda en España son culpables de una crisis económica y migratoria. Finalmente, mediante el empleo de las emociones, Vox ha construido en Santiago Abascal una figura de líder carismático, empoderado y lleno de valores, capaz de acabar con la corrupción, "la dictadura progresista del PSOE y Podemos" y la "derechita cobarde".

El cómputo global de los resultados obtenidos demuestra que tanto los medios de comunicación tradicionales como los nuevos medios digitales analizados han sido 
una herramienta fundamental para que un partido de extrema derecha se implante en el panorama político español. Las televisiones analizadas, en términos generales, han ofrecido minutos y aportado una imagen entre neutra y recabando aspectos positivos de un partido político cuya marca discursiva se ha centrado en el conflicto, la apelación a una crisis de seguridad provocada por los extranjeros, y, como ocurría en la investigación de Rivas-de-Roca et al. (2020: 233), a mencionar directa y negativamente al resto de formaciones independientemente de su ideología.

Finalmente, la comunicación de este partido en Twitter se caracteriza por tener un fuerte componente ideológico; mensajes de odio hacia la cultura árabe y hacia la crisis territorial, tienen una gran presencia en la cuenta oficial. Así, aunque los resultados se consideren relevantes (Gamir, 2020: 77) en el estudio de las herramientas comunicativas que ha utilizado la formación verde y la cobertura emitida por las televisiones, resultaría conveniente analizar en profundidad estas cuestiones incrementando el número de medios a investigar, actores políticos, y por supuesto, diferencias diacrónicas en los discursos desde el nacimiento de la formación hasta sus políticas más recientes. También resultaría relevante investigar en mayor profundidad las campañas electorales futuras de la formación para comprobar la posible existencia de fluctuaciones discursivas en su mensaje, tanto en términos nacionales, como autonómicos y locales.

\section{REFERENCIAS}

Almansa, M. (2019). “El populismo de extrema derecha en los Estados Unidos de la era Trump: De la democracia "sin rostro" a la reacción identitaria", en Anales de la Cátedra Francisco Suárez, n 53, pp. 157-182. Recuperado de: http://dx.doi.org/10.30827/ACFS. v53i0.7947

Alonso, L. (2018). "El discurso populista en Twitter UN análisis comparado del estilo comunicativo de los actores políticos populistas de España, Italia, Francia y Reino Unido", (tesis doctoral), Universitat Jaume I, Castellón.

Altheide, D. y Snow, R. (1979); Media Logic. Beverly Hills, CA: Sage.

Aruguete, N. (2009). "Estableciendo la agenda. Los orígenes y la evolución de la teoría de la Agenda Setting", en Ecos de la Comunicación, vol. 2, n² 2, pp 11-38.

Aruguete, N. (2017). "Agenda building. Revisión de la literatura sobre el proceso de construcción de la agenda mediática", en Signo y Pensamiento, vol. 36, n 70, pp. 36-52.

Aruguete, N. (2019). “¿Twitter acrecienta la polarización política?", en Revista BPolitics, $\mathrm{n}^{\circ}$ 2, pp. 22-25.

Aruguete, N. (2011). "Framing. La perspectiva de las noticias", en La trama de la comunicación, nº 15, pp. 67-80.

Baviera, T.; García-Ull, F. y Cano-Orón, L. (2017), “Twitter: ¿protgonismo vicario?”, en G. López García y L. Valera (eds)., Pantallas electorales. El discurso de partidos, medios y ciudadnos en la campaña de 2015 (pp.167-192). Valencia: Editorial UOC

Bracciale, R. y Martella, A. (2017). "Define the populist political communication style: the case of Italian political leaders on Twitter", en Information, Communication \& Society, vol. 20, no 9, pp. 1310-1329. Recuperado de: https://doi.org/10.1080/136911 8X.2017.1328522 
Campos, E. (2017): “Twitter y la comunicación política”, en El profesional de la información (EPI), vol. 26, $\mathrm{n}^{\circ}$ 5, pp. 785-793.

Canovan, M. (1999). "Trust the people! Populism and the two faces of democracy", en Political studies, vol. 47, $\mathrm{n}^{\circ} 1$, pp. 2-16.

Casero-Ripollés, A. (2014). “La pérdida de valor de la información periodística: causas y consecuencias", en Anuario ThinkEPI, n 8, pp. 256-259. Recuperado de: http://hdl. handle.net/10234/124523

Casero-Ripollés, A. (2012): El periodismo político en España: algunas características definitorias. Cuaderno Artesanos de Latina. La Laguna.

Casero-Ripollés, A., \& Yeste, E. (2014). “La comunicación política hoy: entre nuevos medios y viejas lógicas", en Trípodos. Facultat de Comunicació i Relacions Internacionals Blanquerna-URL, vol. 34, pp. 8- 12.

Chadwick, A. (2013): The hybrid Media System: Politics and Power. Oxford: Oxford University Press.

Dader, J. (2009). “Ciberpolítica en los websites de partidos políticos: la experiencia de las elecciones de 2008 en España ante las tendencias transnacionales", en Revista de sociologia e politica, vol. 17, n³4, pp. 45-62. Recuperado de: https://doi.org/10.1590/ $\underline{\mathrm{S} 0104-44782009000300005}$

Davis, A. (2007). "Investigating journalist influences on political issue agendas at Westminster", en Political communication, vol. 24, n² 2, pp. 181-199. Recuperado de: https://doi.org/10.1080/10584600701313033

Dearing, J., Rogers, E., y Rogers, E. (1996). Agenda-setting (Vol. 6). Sage publications. Thousand Oaks, CA.

Engesser, S,. Fawzi, N,. y Olof, Larsson. (2017) “Populist online communication: introduction to the special issue, InformatioN", en Communication \& Society, vol. 20, No 9, PP. 1279-1292, Recuperado de: 10.1080/1369118X.2017.1328525

Engesser, S., Ernst, N., Esser, F., y Büchel, F. (2017). Populism and social media: How politicians spread a fragmented ideology, en Information, communication \& society, vol. 20, n 8, pp. 1109-1126. Recuperado de: https://doi.org/10.1080/136911 $\underline{8 X .2016 .1207697}$

Entman, R. (2007). "Framing bias: Media in the distribution of power", en Journal of communication, vol. 57, $\mathrm{n}^{\circ}$ 1, pp 163-173. Recuperado de: https://doi.org/10.1111/ j.1460-2466.2006.00336.x

Ernst, N., Engesser, S., Büchel, F., Blassnig, S., y Esser, F. (2017). “Extreme parties and populism: an analysis of Facebook and Twitter across six countries", en Information, Communication \& Society, vol. 20, n 9, pp. 1347-1364. Recuperado de: https://doi.org /10.1080/1369118X.2017.1329333

Errejón, Í. (2015). “We the people El 15-M:¿ Un populismo indignado?", en ACME: An International Journal for Critical Geographies, vol. 14, n 1, pp. 124-156. Recuperado de: https://acme-journal.org/index.php/acme/article/view/1144

Ferreira, C. (2019). "Vox como representante de la derecha radical en España: un estudio sobre su ideología", en Revista Española de Ciencia Política, n 51, pp. 73-98. 
Recuperado de: https://doi.org/10.21308/recp.51.03

Gamir, J. (2015). “Difusión online de las agendas políticas en campaña electoral: El uso de internet en las Elecciones Locales de 2015 en la ciudad de Valencia", (tesis doctoral), Universidad de Valencia, Valencia.

Gamir, J. (2020). "La transmisión digital de las agendas políticas en las Elecciones Locales de 2015 de la ciudad de Valencia", en Revista de Comunicación Política, n² 2, pp. 55-79. Recuperado de: https://doi.org/10.29105/rcp2-3

Gamson, W., y Modigliani, A. (1989). "Media discourse and public opinion on nuclear power: A constructionist approach", en American journal of sociology, vol. 95, n 1, pp. $1-37$.

Gómez, R., Vidales, N., y Torrico, D. (2018). La televisión informativa en el entorno digital: análisis de las ediciones diarias de las cadenas generalistas líderes de audiencia en España, en Estudios sobre el mensaje periodístico, vol. 24, nº 1, pp. 193-212.

Hallin, D., y Mancini, P. (Eds.). (2011): Comparing media systems beyond the Western world. Cambridge University Press.

Hjarvard, S. (2016). “Mediatización: La lógica mediática de las dinámicas cambiantes de la interacción social", en La trama de la comunicación, vol. 20, n 1, pp. 235-252. Recuperado de: http://www.redalyc.org/articulo.oa?id=323944778013

Humanes, M. L., Martínez-N, M., y Saperas, E. (2013). Political journalism in Spain. Practices, roles and attitudes, en Estudios sobre el mensaje periodístico, vol. 19, $\mathrm{n}^{\circ} 2$, pp. 715-731. Recuperado de: https://doi.org/10.5209/rev_ESMP.2013.v19.n2.43467

Humanes, M. L., Sánchez, M. D. M., de Dios, R. M., y López-Berini, A. (2013). “Pluralismo y paralelismo político en la información televisiva en España", en Revista Latina de Comunicación Social, vol. 5, nº 68, pp. 24-16.

López, G. (2017). "Comunicación política y discursos sobre el poder", en El profesional de la información, vol. 26, n 4, pp. 573-578. Recuperado de: https://doi.org/10.3145/ epi.2017.jul.01

López, G., y Valera, L. (2017): Pantallas electorales: el discurso de partidos, medios y ciudadanos en la campaña de 2015. Barcelona: UOC.

López, G., Gamir, J. V., García Ull, F. J., Llorca, G., Cano, L., y González E, J. L. (2015). "El debate sobre Europa en Twitter. Discursos y estrategias de los candidatos de las elecciones al Parlamento Europeo de 2014 en España", en Revista de Estudios Políticos, no 170, pp 213-246. Recuperado de: http://dx.doi.org/10.18042/cepc/rep.170.07

Martín, L. (2019). “Tratamiento informativo de la irrupción de Vox en la esfera pública durante las elecciones autonómicas andaluzas de 2018" (Tesis de pregrado). Universidad del País Vasco, País Vasco.

Marínez, N. M., Humanes, M. L., y Saperas, E. L. (2014). “La mediatización de la política en el periodismo español. Análisis longitudinal de la información política en la prensa de referencia (1980-2010)", en Trípodos, n³4, pp. 41-59.

Mazzoleni, G. (2004): La comunicación política. Madrid: Alianza Editorial.

Mazzoleni, G., y Schulz, W. (1999). “Mediatization” of politics: A challenge for democracy?, 
en Political communication, vol. 16, n³, pp. 247-261. Recuperado de: https://doi. org/10.1080/105846099198613

Moriche de la Cruz, M. (2016). El discurso populista europeo contemporáneo: una comparativa, (Tesis de pregrado), Universidad pontificia Comillas, Madrid.

Mudde, C. (2004). "The populist zeitgeist", en Government and opposition, vol. 39, n 4, pp. 541-563. Recuperado de: https://doi.org/10.1111/j.1477-7053.2004.00135.x

Mudde, C. (2007) Populist Radical Right Parties in Europe. Cambridge: Cambridge University Press.

Navarro, M., y Rodríguez, D. R., (2017). “Política mediatizada: El caso español durante el periodo 2008-2012", en Index. comunicación: Revista científica en el ámbito de la Comunicación Aplicada, vol. 7, nº 1, pp. 143-163.

Öner, S. (2020). Growing Fusion of Populism and Euroscepticism in Italy: A Comparative Analysis of the League and The Five Star Movement, en Tripodos, $\mathrm{n}^{\circ}$ 49, pp. 13-28. Recuperado de: https://doi.org/10.51698/tripodos.2020.49p13-28

Palau-Sampio, D., Carratalá, A., y Valera., L. (2017). “Mediatización y encuadres de campaña. Análisis comparado de la información de partidos y medios en las elecciones generales de 2015", en Profesional de la Información, vol. 26, n 4, pp. 602610. Recuperado de: https://doi.org/10.3145/epi.2017.jul.04

Pan, Z., y Kosicki, G. M. (2001). "Framing as a strategic action in public deliberation. In Framing public life", en Routledge, 51-82.

Pérez-Curiel, C. (2020). "Trend towards extreme right-wing populism on Twitter. An analysis of the influence on leaders, media and users", en Communication \& Society, vol. 33, n², pp. 175-192. Recuperado de: https://doi.org/10.15581/003.33.2.175-192

Pérez, X. S.; Elías, C. y Cepeda, A. M. L. (2018): “El tratamiento de la información política e institucional en TVE", en Revista Latina de Comunicación Social, vol. 73, nº 9, pp. $1072-$ 1089.

Peris, À., López, G., Cano, L., y Fenoll, V. (2020). “Mediatización y mítines durante la campaña a las elecciones autonómicas valencianas de 2019: entre la «lógica mediática» y la «lógica política»", en Debats. Revista de cultura, poder i societat, vol. 134, n 1, pp. 53-70. Recuperado de: https://doi.org/10.28939/iam.debats.134-1.4

Rivas, R.; García, M. y Bezunartea, O. (2020): “The far-right's influence on Twitter during the 2018 Andalusian elections: an approach through political leaders", en Communication \& Society, vol. 33, $\mathrm{n}^{\circ} 2$, pp. 227-242. Recuperado de: https://idus.us.es/ handle/11441/95535

Roberts, K. M. (2017). “Variedades de capitalismo y subtipos de populismo: las bases estructurales de la divergencia política", en Revista SAAP. Publicación de Ciencia Política de la Sociedad Argentina de Análisis Político, vol. 11, n 2, pp. 227-240.

Rodríguez, A., y Uceda, D. (2011). “Diez razones para el uso de Twitter como herramienta en la comunicación política y electoral", en Comunicación y pluralismo, nº 10, pp. 89-116.

Rydgren, J. (2017). "Radical right-wing parties in Europe: What's populism got to do with it?", en Journal of Language and Politics, vol. 16, n 4, pp. 85-496. Recuperado de: https://doi.org/10.1075/jlp.17024.ryd 
Sádaba, T., Rodríguez, J, V. (2007). "La construcción de la agenda de los medios: el debate del Estatut en la presnea española", en Ámbitos, vol. 10, n 16, pp. 187-211. Recuperado de: http://dx.doi.org/10.12795/Ambitos.2007.i16.10

Savarino, F. (2006): "Populismo: perspectivas europeas y latinoamericanas", en Espiral (Guadalajara), vol. 13, $\mathrm{n}^{\circ}$ 37, pp. 77-94.

Taggart, P. (2004). "Populism and representative politics in contemporary Europe", en Journal of political ideologies, vol. 9, n³, pp. 269-288.

Strömbäck, J. (2008). "Four Phases of Mediatization: An Analysis of the Mediatization of Politics", en The International Journa of Press/Politics, vol. 13, n 3, pp. 228-246. Recuperado de: https://doi.org/10.1177/1940161208319097

Valera, L. (2012). “Blogs ciudadanos en las elecciones españolas de 2008: asimilación de la agenda y reproducción de la lógica partidista", en Ámbitos: Revista Internacional de Comunicación, $\mathrm{n}^{\circ}$ 21, pp 207-229. Recuperado de: http://hdl.handle.net/11441/67431

Valera, L., y López, G. (2014). "Agenda y marcos en las webs de PP y PSOE en la cibercampaña de 2011", en Revista Latina de Comunicación Social, n 69, pp. 41-66. Recuperado de: 10.4185/RLCS-2014-1000

Valera, L., Calvo, D.,y López, G. (2018). “Conversaciones políticas en Facebook. Explorando el papel de la homofilia en la argumentación y la interacción comunicativa", en Revista Latina de Comunicación Social, nº 73, pp. 55-73. Recuperado de: 10.4185/RLCS-20181245

Vázquez, T. y Campos, M.V. (2020). “El contra debate de Vox en Twitter: boicot, ninguneo y mensajes antisistema", en Sphera Publica, vol. 2, n 20, pp. 51-72.

Waisbord, S. (2020). ¿Es válido atribuir la polarización política a la comunicación digital? Sobre burbujas, plataformas y polarización afectiva, en Revista SAAP, vol. 14, n 2 , pp. 249-279. Recuperado de: https://doi.org/10.46468/rsaap.14.2.A1 


\section{ANEXO}

\section{VARIABLES DE IDENTIFICACIÓN}

\section{1-Tipo de publicación}
a. Programa de TV
b. Cuenta de Twitter

\section{2- Cadena}
a. TVE
b. Telecinco

\section{3- Fecha}

a. Campaña electoral del 28 de abril de 2019

b. Campaña electoral del 10 de noviembre de 2019

4- Título (para todo excepto Twitter)

\section{ENFOQUE TEMÁTICO Y RELEVANCIA DE LA NOTICIA/ TUIT}

\section{5- Tema de la noticia/ tuit}

a. Policy issues

1.1.1. Empleo/ Desempleo

1.1.2. Impuestos, Recortes económicos y sociales (economía)

1.1.3. Deuda pública, vivienda y balanzas fiscales

1.1.4. Desigualdades

1.1.5. Empresas

1.1.6. Turismo

1.1.7. Educación

1.1.8. Sanidad

1.1.9. Seguridad ciudadana y justicia

1.1.10. Familia

1.1.11. Inmigración

1.1.12. Pensiones

1.1.13. Organización territorial del Estado

1.1.14. Nacionalismo

1.1.15. Independentismo catalán

1.1.16. Emigrantes - españoles en el exterior

1.1.17. Infraestructuras

1.1.18. Manipulación informativa

1.1.19. Política internacional

1.1.20. Cultura
1.1.21. Canon digital

1.1.22. Nuevas tecnologías

1.1.23. Políticas de desigualdad / Derechos sociales

1.1.24. Ley del aborto

1.1.25. Utilización electoralista de fondos públicos

1.1.26. Agricultura

1.1.27. Unión Europea

1.1.28. Problemas urbanísticos

1.1.29. Industria

1.1.30. Medio ambiente

1.1.31. Memoria histórica

1.1.32. Iglesia

1.1.33. Fiestas, tradiciones

1.1.34. Corrupción

1.1.35. Grandes proyectos

1.1.36. Deportes

1.1.37. Violencia de género

1.1.38. Terrorismo

1.1.39. Puertas giratorias

b. Campaign issues

1.1.1. Eventos de campaña

1.1.2. Organización de campaña

1.1.3. Estrategias de campaña

1.1.4. Anécdotas. Aspectos no políticos de campaña (cuestiones estéticas, frivolidades, etc.) 
c. Political issues

\subsubsection{Sondeos}

1.1.2. Coaliciones de partidos

1.1.3. Estimación de resultados

1.1.4. Programas electorales

1.1.5. Participación vs Abstención

1.1.6. Debates electorales

1.1.7. Crispación (ir contra partidos, fake news, luchas contra el propio partido)

1.1.8. Relación con otros actores sociales

1.1.9. Política interna del partido

1.1.10. Resultados electorales

1.1.11. Regeneración democrática

1.1.12. Voto rogado (voto por correo desde el extranjero)

1.1.13. Otros

\section{d. Personal issues}

Candidatos (personalidad, cualidades)

\section{6- Valoración sobre el protagonista}

a. Negativa (para el partido o actores políticos de VOX)

b. Neutral (para el partido o actores políticos de VOX)

c. Positiva (para el partido o actores políticos de VOX)

\section{7- Duración de la noticia}
a. De 0 a 30 segundos
b. De 30 segundos a 1 minuto
c. De 1 minuto a 1:30.
d. Más de 2 minutos

\section{8- Posición de la noticia}
a. Aparece en sumario
b. No aparece en sumario

\section{9- Orden de aparición de la noticia}

Indicar el orden de aparición con respecto al resto de partidos

\section{0- Contiene recursos audiovisuales}
a. Solo video
b. Video y audio simultáneo
c. Solo audio
d. Gráficos o esquemas 


\section{ELEMENTOS DEL DISCURSO POPULISTA EN TWITTER}

\section{1- Apelación al 'pueblo'}
a. Sí
b. No

12- Término utilizado para apelar al 'pueblo'
a. Pueblo
b. La gente
c. La patria
d. Nosotros
e. Los españoles
f. La España que madruga
g. La clase trabajadora
h. Compatriotas
i. La España Viva
j.Otros (indicar)

\section{3- Crítica a las 'élites'}
a. Sí
b. No

14- Actor al que va dirigida la crítica
a. Élites políticas
b. Élites económicas
c. Instituciones
d. Establishment
e. Sistema judicial
f. Élites mediáticas
g. Gobierno
h. Oligarquía
i. Otros (indicar)

\section{5- Crítica a otros colectivos}
a. Sí (indicar)
b. No

16- Críticas al euroescepticismo
a. Sí
b. No

17- Referencias a las crisis
a. Sí
b. No

18- Tipo de alusión a esa crisis
a. Crisis de valores
b. Crisis social y crisis política
c. Crisis económica
d. Crisis migratoria
e. Crisis de seguridad/terrorismo
f. Crisis del modelo territorial español

19- Ensalzamiento de la figura del líder
a. Sí
b. No

\section{0- Apelación a las emociones}
a. Sí
b. No 